\title{
Obra en prosa sobre la veríssima inmaculada conceptió de la Mare de Déu (Valencia, Lambert Palmart, 1488): estudio material de un incunable perdido
}

\author{
Josep Lluís MarTos \\ Universidad de Alicante \\ jl.martos@ua.es
}

Desde finales del siglo XIX, se ha reconocido a Lambert Palmart como el primero de los impresores valencianos, en un interesante episodio de interacción bibliográfica entre Konrad Haebler y José Enrique Serrano y Morales, del que no solo queda noticia en sus obras, sino también en la correspondencia que ambos mantuvieron durante los primeros meses de 1897 (Martos 2021: 28-31). Con esto, se atribuye a su taller el primero de los cancioneros incunables hispánicos, que Brian Dutton (1990-1991: v: 1-2) catalogó como $74 * \mathrm{LV}$, ocho años anterior a 82IM, en este caso ya con colofón completo ${ }^{1}$ : «CFecha en çamora a veynte $\mathrm{y} \mid$ çinco de henero año de lxxxij. | Centenera» (h. e7v) ${ }^{2}$. En la imprenta valenciana tenemos que esperar aún más, hasta trece años, para documentar otro impreso poético: el 14 de abril de 1487, Lambert Palmart, de nuevo, lleva a las prensas un incunable también derivado de un certamen poético valenciano ${ }^{3}$, como en el caso de $74 * \mathrm{LV}$. Dutton no recoge esta fuente en su catálogo, a pesar de contener una composición en castellano de

\footnotetext{
"Este trabajo se enmarca en el proyecto Cancionero, Romancero y Fuentes Impresas del Ministerio de Economía, Industria y Competitividad (FFI2017-86313-P) (AEI/FEDER, UE), del cual soy investigador principal. Cuenta con el permiso de reproducción de fotografías provenientes del microfilm del incunable perdido objeto de este trabajo (1488), que encargó Pere Bohigas para la Biblioteca de Catalunya en 1963, así como de sus fichas correspondientes en el catálogo manual de microfilms, lo que agradezco a Margarida Losantos (BNC). Asimismo, para los permisos de reproducción de la primera página de texto de los incunables de 1487 y 1489, agradezco, respectivamente, su concesión a Neus Anna Verger (CRAI Biblioteca de Reserva. Universitat de Barcelona) y Anne-Guylaine Foret (Collections des Musées de Langres).

${ }^{1}$ De $82 * \mathrm{GM}, 82 * \mathrm{IM}$ y $82 * \mathrm{JM}$ no sabemos la fecha exacta e, incluso, este último parece no ser un incunable independiente, sino un cuaderno sin signatura del segundo de estos impresos poéticos.

${ }^{2}$ El ejemplar único que nos ha llegado se conserva en la Biblioteca Nacional de España, con signatura INC/2159.

${ }^{3}$ Para la materialidad de este incunable y su estructura en relación al certamen original, véase Martos 2019a y 2019b, mientras que para el estudio de sus dos ejemplares remito a Martos 2019c.
} 
Juan Tallante (ID 6046) $)^{4}$, de manera que, siguiendo su modelo de siglas, deberíamos incorporarla «quizás denominándola $87 \mathrm{FD}$, por el año de impresión y las iniciales de su editor y responsable literario, Ferrando Díeç» (Martos 2018: 532) . Este segundo cancionero incunable valenciano $^{6}$ tiene especial interés porque inicia una trilogía de impresos que, a su vez, responde a un programa de certámenes sobre la Inmaculada Concepción patrocinados por Ferrando Díeç, por lo que debe ser considerado, asimismo, el promotor o editor de estas obras, mientras que Lambert Palmart fue su impresor.

\section{UNA TRILOGÍA DE INCUNABLES VALENCIANOS}

\section{El incunable de la Obra de la sacratíssima Conceptió de la inteme-} rada mare de Déu (87FD) es fruto, por tanto, de uno de los certámenes valencianos cuatrocentistas y el primero de los tres que Ferrando Díeç dedicó a la Inmaculada Concepción, en el clima inmediato que generaron las disposiciones de Sixto IV de 1483 y 1484 a favor de la Purísima, que pretendían acabar con siglos de debate teológico, si no enconados enfrentamientos entre órdenes religiosas, que llegaron a generar importantes crisis en la Iglesia, como el concilio cismático de Basilea o los duros ataques dominicos del principio del pontificado de este papa franciscano. No afectaban, exclusivamente, a la más alta estructura eclesiástica, sino que eran un día a día en las ciudades europeas, en general, y en Valencia, en particular, unos debates de los que se hace eco la literatura de la época ${ }^{7}$ y un posicionamiento dominico que se cuestiona desde

\footnotetext{
${ }^{4}$ Recogida en segundo lugar en el Cancionero general de 1511 y en todas sus ediciones posteriores.

${ }^{5}$ Solo unos meses antes, el 31 de enero de 1487, Nicolau Calafat imprime en Palma un incunable con ocho composiciones poéticas en catalán (Forteza Oliver 2011: 37-52 y 96-97, n. ${ }^{\circ}$ 2), que, en la tradición bibliogràfica propia, conocemos por Massó i Torrents (1932: 347-351) como impreso $b^{l}$, mientras que el incunable de Palmart de ese mismo año sería $b^{2}$ y el de 1474 se cataloga como $a$. En su Bibliografía dels antics poetes catalans, aún no conocía el impreso mallorquín de Caldentay y, por esta razón, identifica el de Palmart de ese mismo año simplemente como $b$. Remito, sin embargo, a este trabajo para la estructura interna de ambos incunables valencianos (Massó i Torrents 1913-1914: 238-244), que abrevia en su Repertori de 1932

${ }^{6} \mathrm{El}$ tercero y último de los cancioneros incunables valencianos se deriva también de un certamen poético, en este caso dedicado a san Cristóbal, que se celebró en 1488, el mismo año que el tercero de los dedicados a la Inmaculada Concepción. Para este incunable poético, véase Martos 2016a y 2016b.

${ }^{7}$ Como es el caso del Spill de Jaume Roig, que recoge el clima social de este tipo de debates en la Valencia de los años previos a este certamen poético: «Pluralitat de doctós sans / grans discordants, / d'opinió / la qüestió / ret fort dubtosa, / dificultosa / de decidir / lo sostenir / lo hoc o no, / conclusió és de fatiga / dels sants antiga, / d'abdós les parts / de saber farts / tots aprobats / canonizats» (Guix 1954: 290); «lo disputar / grans qüestions / en los sermons, / impreceptibles, / no aprensibles, / subtilitats, / alietats / de Trinitat, / si en peccat / fon concebuda, / si fos remuda, / predestinar, / la fe provar, / dits d'en Pertusa, / d'en Llull sa musa, / de Ocam, ascot / llur vari vot, / coses molt primes / ab sutil rimes / plau a les gents; / profit no gens / ne sol restar» (Ferrando 1983: 381-382).
} 
la mismísima convocatoria del certamen de $1486^{8}$, pero también desde los textos poéticos a él presentados ${ }^{9}$. La celebración de la festividad de la Inmaculada en las diferentes diócesis -incluida la sede pontifical de Roma- era una realidad que ayudaba a difundir el postulado teológico entre los fieles y que, sin embargo, contrastaba con la ausencia de un reconocimiento dogmático para este misterio mariano ${ }^{10}$.

En medio de este clima y como resultado de él, Ferrando Díeç patrocinó un certamen poético sobre la Inmaculada Concepción en 1486, cuyo éxito debió de ser el germen del convocado en 1487, sobre este mismo tema, pero en prosa en lengua romance, desde el cual, a su vez, se evolucionó a un nuevo certamen en 1488, en esta ocasión en prosa latina. Los tres certámenes dieron lugar a sus respectivos incunables, que, en todos los casos, se limitaron a una selección de los textos y se imprimieron al año siguiente de su celebración, al tener lugar siempre en una fecha tan tardía como la festividad de la Inmaculada, el 8 de diciembre, con entrega de premios, incluso, en los meses posteriores ${ }^{11}$.

\begin{tabular}{|c|c|c|c|}
\hline Textos & CERTAMEN & INCUNABLE & TÍTULO DEL INCUNABLE ${ }^{12}$ \\
\hline poesía & 1486 & 1487 & $\begin{array}{l}\text { Obra de la sacratíssima conceptió de la } \\
\text { intemerada mare de Déu }\end{array}$ \\
\hline $\begin{array}{l}\text { prosa } \\
\text { en romance }\end{array}$ & 1487 & 1488 & $\begin{array}{l}\text { Obra en }{ }^{13} \text { prosa sobre la veríssima } \\
\text { inmaculada conceptió de la Mare de Déu }\end{array}$ \\
\hline prosa en latín & 1488 & 1489 & $\begin{array}{l}\text { Orationes ad laudem purissime } \\
\text { conceptionis Virginis Marie }\end{array}$ \\
\hline
\end{tabular}

La evolución de un modelo de certamen a otro es connatural, en última instancia, a la importante dosis de teología que impregnaba los tres eventos, en contraste con los posicionamientos fundamentalmente

\footnotetext{
${ }^{8}$ En el primero, más extenso y de mayor alcance de los llibells, el que convoca al premio principal, el robí, Ferran Dies establece la siguiente norma del concurso: «No admetent dients en lo contrari / ni sols legir en huna tan gran plaça, / puix tal laor no us plau de l'adversari» (vv. 61-63; Ferrando 1983: 433).

${ }^{9}$ Véase, por ejemplo, los dos que destaca Martínez Romero (2015: 349): «l'apostròfe de Jordi Centelles als dominicans, tradicionalment maculistes: "Ö̈u, predicadors, les santes doctrines, / gustau un poquet d'aquest lletovari" (vv. 25-26). Curiosament, el fet que "contra els malignes / de pricadors frares ['dominicans'] raons diu insignes" valgué guanyar "lo marsapà" a Lluís Roís».

${ }^{10}$ Para los contextos que enmarcan la convocatoria de este certamen y, en última instancia, la impresión del incunable objeto de este trabajo, véase Martos, en prensa.

${ }^{11}$ Así ocurrió, de hecho, con la sentencia de los cuatro premios del certamen que dio lugar a este incunable en cuestión: la del radix Jesse se publicó el 11 de septiembre de 1486, la del marsapà se falló el 18 de diciembre (día de la Esperanza), mientras que la lectura de la sentencia de la carta de navegar y del robi se produjo ya el 2 de febrero de 1487 (día de la Candelaria).

${ }^{12}$ Extraído de la rúbrica inicial, de una cierta extensión, para los incunables de 1487 y 1488, así como del colofón para el de 1489 , porque ninguno de los tres tiene, sensu stricto, portada con un título.

$\left.{ }^{13} \mathrm{en}\right]$ in
} 
estéticos y literarios sobre los que se construían las poesías de Les trobes en $1474^{14}$. El propio Ferrando Díeç dejaba claro al inicio del incunable de 1488 las razones por las cuales se evolucionó de la poesía a los textos en prosa plana esto es, en vulgar o romance, y, de ahí, es fácil entender por qué se dio el paso a la prosa latina, como vehículo teológico:

Perquant subiugat resta lo dir en co | bles ab innumerables vicis que per al art se requir esquiuar | E per lo semblant: perque en lo passat any donant yo $\mid$ quatre ioyes en rims se condolien molts com en prosa | plana dir no si podia. principalment mogut per fer més | estesa la infallible veritat dela purissima conceptio dela $\mid$ mare de deu. E per condescendre a tants bons dehidors | en la prosa: vn robi en or engastat haura lo mils dient. | Apres de nou jorns iutjat: essent la plaça per a dir. En | lo insigne monestir dels frares dela verge maria del $\mid$ carme. jorn purissim de tan purissima conceptio. |.Ferrando dieç preuere. (h. alv).

Ya desde los repertorios de Hernando Colón del siglo XVI tenemos noticia de un ejemplar del incunable poético de 1487 (Askins 1988: 4647), que no se correspondería con ninguno de los dos conservados en la actualidad $^{15}$ : uno en la Biblioteca Universitària de Barcelona (Inc. 263) y otro en la Hispanic Society of America, en Nueva York ${ }^{16}$. Esta edición es bien conocida por la incunabilística internacional y se ha incorporado a la mayoría de los principales catálogos bibliográficos desde el siglo XVIII hasta la actualidad ${ }^{17}$ : Antonio 1788 , II: 324, n. $^{0} 755$; Ximeno 17471749, I: 53-54; Rodríguez 1747: 125; Cerdá y Rico 1778: 337-339; Hain 1826-1838, I/2: 253, n. ${ }^{\circ}$ 6163; Méndez 1861: 37; Brunet 1861: 678; Gallardo 1863-1889, II: 793-797, n. ${ }^{\circ}$ 2046; Salvá 1872, I: 141, n. ${ }^{\circ} 301$; Ferrer y Bigné 1873: 63-64; Copinger 1895-1902, II/2: 307, n. ${ }^{\circ} 1975$ b; Haebler 1897: 91-92; Serrano y Morales 1898-1899: 450-451; Haebler 1903-1917: I, 105 y II, 63, n. ${ }^{\circ}$ 228; Massó i Torrents 1913-1914: 242244; Ribelles Comín 1915: 139-141; Aguiló 1923: 540, n. ${ }^{\circ}$ 2095; Martí Grajales 1927: 191-192; Massó i Torrents 1932: 50-51; Stillwell 1940: D-151; Blázquez 1945: 57, n. ${ }^{\circ} 263$; Vindel 1946: 72-74, n. ${ }^{\circ} 24$; Vindel 1951: 205, n. ${ }^{\circ}$ 24; Goff 1973: D-192; Concheff 1985: 61, n. ${ }^{\circ}$ 647; García Craviotto 1989-1990, I: 325, n. ${ }^{\circ} 2096$; Lamarca \& Torra 1995: 94 ,

${ }^{14}$ Véase Ferrando Francés (1983: 380-381).

${ }^{15}$ Como sugiere Askins (1988: 47): «Curiosa la coincidencia de faltas entre el ejemplar de Colón y el de Gallardo que se conserva actualmente en la Hispanic Society of America». Para este tema y para los ejemplares conservados del cancionero incunable de 1487, véase Martos (2019c).

${ }^{16}$ En la Hispanic Society of America, los incunables no tienen signatura propiamente dicha, sino que se catalogan como Incunabula.

${ }^{17}$ Además, recientemente se le han dedicado trabajos específicos sobre la materialidad de la edición (Martos 2019a), sobre su estructura como cancionero incunable (Martos 2019b), sobre los ejemplares conservados (Martos 2019c) y sobre los fantasmas bibliográficos que, alrededor de él, se generaron en la bibliografía ilustrada (Martos 2020a). 


\section{n. ${ }^{\circ}$ 256; Romero Lucas 2005, II: 123-125, n. ${ }^{\circ} 23$; BITECA manid 1452; GW 08343; ISTC id00192000.}

Frente a estas amplias noticias del primero de los incunables de esta trilogía inmaculista, destaca el desconocimiento y la confusión generada durante siglos alrededor de los dos impresos posteriores, de 1488 y de 1489 , respectivamente ${ }^{18}$. Si bien del datado en $1489^{19}$ se podrían haber catalogado incluso hasta dos ejemplares en los repertorios de Hernando Colón (Askins 1988: 44 y 46; Martos 2020b), desde ese temprano siglo XVI no se vuelve a tener noticia bibliográfica de esta edición incunable hasta el último tercio del siglo XIx, gracias a que formó parte de la biblioteca de Bartolomé José Gallardo (1863-1889, II: 797-798, n. ${ }^{\circ}$ $2047)^{20}$. En su catálogo se incluyó una noticia de este incunable de la que dependía la poca bibliografía posterior que la llegó a recoger (Copinger 1895-1902, II: 307, n. ${ }^{o} 1975 \mathrm{a}$; Haebler 1897: 92; Serrano y Morales 1898-1899: 451; Haebler 1903-1917, r: 105, n. ${ }^{\circ} 229$; Vindel 1946: 76, n. ${ }^{\circ}$ 26; Palau y Dulcet 1948-1977, Iv: n. ${ }^{\circ}$ 73676), hasta que Arnoult (1979: 107, n. ${ }^{\circ} 525$ y 393, n. $\left.{ }^{\circ} 149\right)$ lo localizó como Inc. 44 de la Société Historique et Archéologique de Langres (SHAL), en el primer volumen de los Catalogues régionaux des incunables des bibliothèques publiques de France, el dedicado a las Bibliothèques de la Région ChampagneArdenne. Allí lo localizan aún hoy el Gesamtkatalog der Wiegendrucke «Langres SocHist» (GW 08344) y el Incunabula Short Title Catalogue «Langres SHAL» (ISTC id00192100), del último de los cuales depende Romero Lucas (2005, II: 129-130, n. $\left.{ }^{\circ} 25\right)$, que evidenciaba que no

\footnotetext{
${ }^{18}$ No hay ningún catálogo o repertorio que contenga los tres incunables, lo que, junto a la pérdida de los dos ejemplares únicos de 1488 y 1489, generó cierta confusión, de la que, para no ir más lejos, puede ser ejemplo Martos (2008: 12), donde se le da el título del tercer incunable al segundo, corregida en Martos (2015: 131).

${ }^{19}$ Para la datación del incunable, véase el epígrafe dedicado en Martos (2019d: 79-83), puesto que la transcripción del colofón realizada por Gallardo generó mucho desconcierto bibliográfico: «quarto kalendas marcij. anno a natiuitate domini. M.cccc.lxxxviij» (1865-1889, II: 797, n. $^{\circ}$ 2047). A este error contribuyó la fecha a tinta en su cubierta, corregida posteriormente.

${ }^{20}$ «Tenemos constancia de que la descripción de este impreso depende de sus fichas originales -pues las que no son de su autoría se marcan con un asterisco-, pero también la tenemos de que este incunable le perteneció fehacientememte, porque buena parte de este catálogo, como indica su título, es el de una biblioteca concreta, la del propio Gallardo, y de ella formaban parte la mayoría de los libros descritos. Pero esto no solo lo sabemos implícitamente, sino que Gallardo lo explicita, aunque no en esta entrada de su catálogo, sino en la anterior, de cuyo incunable en cuestión advertía que "el impresor, si mal no me acuerdo, era Lamberto Palmart, donde imprimió en $4 .^{\circ} \mathrm{el} \mathrm{mismo} \mathrm{mosen} \mathrm{Fernando} \mathrm{Diez} \mathrm{las} \mathrm{'Oraciones} \mathrm{latinas'} \mathrm{pronunciadas} \mathrm{en}$ este certámen de la virgen por Miguel Perez, Juan Lopez, Mateo Perez, Dr. Fernando Belluga, Estéban Costa, etc., libro también escasísimo, de que poseo ejemplar, único que he alcanzado á ver, ni sepa que nadie vió otro tal" (Gallardo 1863-1889, II: 797, n. ${ }^{\circ} 2046$ ). Era consciente, por tanto, de la singularidad de este ejemplar de su biblioteca. Por ello, confinado en una o varias bibliotecas privadas, la pérdida de su rastro tras su muerte limitó el conocimiento de este incunable por parte de los bibliógrafos y de la crítica especializada durante alrededor de un siglo» (Martos 2019d: 65).
} 
había podido conseguir reproducción del ejemplar ${ }^{21}$, sin duda por los problemas de comunicación con un fondo que ya no lo custodiaba ${ }^{22}$. La entrada catalográfica de Arnoult era más concisa aun que la de Gallardo, por lo que no se ampliaba el conocimiento de este incunable, para lo cual seguían siendo un referente los datos de este último ${ }^{23}$, ni se pudo avanzar tampoco con posterioridad a él, porque en 1985 dejó de estar en la SHAL, el fondo al que se refiere la bibliografía posterior, a excepción de un reciente trabajo, que no solo lo localiza ya en los Musées de Langres, sino que explica la historia del ejemplar hasta su recuperación, para, definitivamente, ofrecer un estudio material e interno de este incunable tan desconocido (Martos 2019d: 83-91).

\section{BIBLIOFILIA Y PÉRDIDA DEL INCUNABLE DE 1488}

La posesión privada de ejemplares únicos de impresos conlleva su inadvertencia por buena parte de la crítica, que no siempre tiene acceso a esas bibliotecas, ni tampoco saben de sus contenidos. Además, un cambio de poseedor puede suponer, incluso, la pérdida de ese rastro, conocido por unos pocos privilegiados de la misma generación, que se llevan con ellos la memoria, lo que acaba dando lugar a bibliografía perdida y, en consecuencia, a menudo también a literatura perdida. Su escasa presencia en los repertorios es consecuencia de ello y, de hecho, lo delata. Podría aportar diferentes ejemplos de otros incunables en circunstancias similares, en los que estoy trabajando, con la necesaria paciencia que exige la investigación en literatura perdida, por las dificultades connaturales al propio mercado del libro y por los rastros difusos que emergen de la privacidad de las bibliotecas. Pero, en este sentido, quisiera destacar, precisamente, el incunable que es objeto de este trabajo, el segundo de los que forman parte de esta trilogía valenciana de Lambert Palmart, absolutamente desconocido por la incunabilística internacional y que emergió hace poco más de cincuenta años en el ámbito de la bibliografía

\footnotetext{
${ }^{21}$ «En el ISTC se indica que un ejemplar de esta obra se encuentra em la Biblioteca se la Sociedad Arqueológica e Histórica de Langres (Francia). La obra no ha podido llegar a tiempo para incluir las imágenes» (Lucas 2005, II: 129-130, n. $\left.{ }^{\circ} 25\right)$.

22 «Entre 1976 y 1977, la SHAL firmó un convenio con las autoridades municipales de Langres para que fuesen ellos los que se encargasen de la conservación del patrimonio y a este fin se contrató a Gérard Tisserand como primer conservador de los museos de Langres. Como fruto de este convenio nació el nuevo emplazamiento del Musée d'Art et d'Histoire de Langres, destinado a reunir los fondos de Saint-Didier y Breuil en un edificio de estilo contemporáneo, inaugurado en 1995. Un año después, en 1996, llegan a este nuevo emplazamiento, provenientes del Musée Breuil, los incunables de la SHAL» (Martos 2019d: 75).

${ }^{23} \ll 4^{\circ}$. - - l. g. - Hermosa impresion en buen papel, sin foliacion ni reclamos, pero con signaturas a-c (ésta de á 10 foj., las otras de á 8 foj.)» (Gallardo 1863-1889, II: 797, n. ${ }^{\circ} 2047$ ). Siguiendo los datos físicos aportados por este, Haebler desarrolla así la correspondiente ficha bibliográfica: «Diez, Fern. Orationes ad laudem purissimae conceptionis. - Valencia, por Lamberto Palmart, 1488,26 de febrero. $-4^{\circ} .-26$ hjs no fols. — sign: $\mathrm{ab}^{8} \mathrm{c}^{10}$. — á linea tirada. - letra gótica» (Haebler 1903-1917, r: 105, n. ${ }^{\circ} 229$ ).
} 
específica de filología catalana. Y en ese ámbito se ha quedado, esperemos que hasta hoy ${ }^{24}$.

Del incunable conmemorativo del certamen inmaculista en prosa en vulgar, impreso también en Valencia por Lambert Palmart, en este caso en 1488, nos llega su primera noticia en 1964, gracias a una serie de casualidades, entre las que destaca el hecho de contener una obra de Joan Roís de Corella desconocida hasta entonces, la Vesió a la porta de la Senyora Nostra de Gràcia, de la que da primicia Martí de Riquer en su Història de la literatura catalana (1964, III: 280-283). A propósito de ello, en el capítulo dedicado a este autor, refiere sintéticamente los contenidos de este incunable, sin atender a los paratextos ${ }^{25}$, y es en nota a pie de página donde ofrece el íncipit, aglutinando la invocación verbal y las primeras líneas de la rúbrica inicial, así como el colofón completo ${ }^{26}$. Pero los datos más interesantes al objeto de este trabajo son aquellos con los que cierra esta nota: «Exemplar de propietat particular, del qual m'ha donat notícia el senyor Pere Bohigas. Li agraeixo la seva amabilitat» (Riquer 1964, III: 280-281, n. 37).

A simple vista, la situación es muy parecida a la del incunable de Gallardo, el tercero de la trilogía, porque, en ambos casos, pertenecía a una biblioteca privada, pero sí sabíamos el nombre del entonces poseedor del impreso de 1489 y, además, aunque un siglo y medio después, el ejemplar ha sido localizado y está a disposición de los investigadores. Riquer, sin embargo, por esa prudencia a la que me refería anteriormente, no desveló el nombre del bibliófilo que poseía este ejemplar a principios de la década de los 60 del siglo pasado y tal circunstancia ha contribuido a que hoy no haya aparecido físicamente aún y a que ni siquiera tengamos un hilo fehaciente del que tirar, al menos hasta hace unos días, porque, finalmente, he podido documentarlo, como veremos. Si bien es cierto que, aún hoy, estamos ante un incunable perdido, como lo estuvo en su día el de Gallardo, sin embargo, tal y como, por primera vez, advierte Antoni Ferrando (1983: 535), «existeix una còpia microfilmada a

\footnotetext{
${ }^{24}$ Puesto que informaré de la existencia de este incunable a los principales proyectos internacionales sobre incunabilística.

${ }^{25}$ «El 28 de juny del 1488 l'impressor Lambert Palmar publicava a València un avui rar opuscle, tot en prosa, que conté el cartell de Ferrando Dieç, la Vesió de Joan Roís de Corella, l'obra premiada, de la qual és autor "lo digne Mossèn Dimas", o sia Bartomeu Dimas (que també concorregué a les justes poètiques religioses del 1474 i del 1488; veg. pàg. 373 i 378 ) i un sermó del barceloní mestre Felip de Malla (veg. pàg. 395)» (Riquer 1964, III: 280).

${ }^{26}$ «Incunable que s'inicia amb els mots: "Jhesus Marie filius. Comença la excellentissima obra en prosa sobre la verissima immaculada conceptio de la mare de Déu a instantia del noble mossen Ferrando Dieç, prevere...”, i fineix amb el colofó: "A lahor e honor de la purissima conceptio de la verge Maria, e a instancia del noble Ferrando Dieç, prevere, foren empremptades e acabades les presents obres ab lo present sermo de mestre Felip de Malla que ell feu en Barcelona a Santa Maria del Mar, per Lambert Palmart, alemany, en la insigne ciutat de Valentia, en l'any de la nativitat de nostre senyor Deu mil CCCC LXXXVIII a XXVIII de juny, vespre de sanct Pere"» (Riquer 1964, III: 280-281, n. 37).
} 
la Biblioteca de Catalunya», por lo que, desde el momento en que esta se efectuó, hubo acceso a sus contenidos ${ }^{27}$.

Ferrando utilizó esta reproducción para estudiar internamente el opúsculo y para transcribir los textos, a excepción de la Vesió a la porta de la Senyora Nostra de Gràcia de Joan Roís de Corella y del sermón inmaculista de Felip de Malla, que, en este último caso, lógicamente, no debió de formar parte del certamen, si no es que se recitó como autoridad teológica, aunque creo que su inclusión en el incunable responde a otros criterios (Martos, en prensa). A partir de esta noticia del microfilm y de la innovación textual que implicaba, Curt Wittlin (1995) edita por primera vez la obra de Corella ${ }^{28}$, mientras que, por lo que respecta al incunable en sí, se limita a plantearse, para negarlo, si se trataba de un ejemplar falso ${ }^{29}$. Con la existencia del microfilm, por tanto, sus contenidos dejaron de ser literatura perdida y a ello contribuyeron también las complementarias ediciones de Ferrando (1983: 541-555) y de Curt Wittlin (1995: 262-268) ${ }^{30}$, dos importantes vías para la conservación de las obras literarias, como, en su día, destacó Alan Deyermond ${ }^{31}$.

Debió de ser Pere Bohigas quien, durante su vinculación a la Biblioteca de Catalunya encargase tal microfilm, donde, tras el paréntesis de la Guerra Civil, fue jefe de la sección de manuscritos entre 1942 y $1971^{32}$. He podido documentar que el primer lector de microfilms se instala en esta

${ }^{27}$ A pesar de las dificultades para localizar el microfilm, puesto que, en tanto que no lo es, no se incluye en el catálogo de fondos propios, como veremos.

${ }^{28}$ Pendiente aún de una edición crítica, porque, lógicamente, el incunable y/o su reproducción eran desconocidos para Miquel i Planas (1913) y la de Wittlin no lo era, si bien ha cubierto una importante función científica.

${ }^{29}$ Bajo la estela, sin duda, del entonces reciente trabajo de Jaume Riera i Sans (1993), de gran repercusión mediática, por poner en tela de juicio, entre otros, la autenticidad del Curial e Güelfa: «Sense poder consultar el volum mateix, resulta difícil respondre a la qüestió -gens supèrflua en el cas d'un incunable desconegut abans del segle vint- de si es tracta veritablement d'una impressió del 1488. [...] Però és ben inversemblant que un falsari s'hagi posat a inventar tres tractats -en català i en llatí- sobre la immaculada concepció, quan era tan fàcil de trobar-ne d'inèdits. A més, la crítica interna del text de Corella-la llengua, l'estil, les idees- no fan dubtar en res de la sedua autenticitat» (Wittlin 1995: 258).

${ }^{30}$ Con ellas, contaríamos con una edición de todos los textos únicos de este incunable y solo faltaría por editar el sermón inmaculista de Felip de Malla, que, sin embargo, cuenta con una versión manuscrita en el Ms. 1112 (ff. 116r-138r) de la Biblioteca de l'Abadia de Montserrat.

${ }^{31}$ «Varias obras medievales se han perdido en los últimos cien años, aunque la publicación de muchos textos, y el empleo cada vez más frecuente del microfilm, consiguen que la pérdida de un códice o de un libro impreso único no signifique la pérdida de la obra literaria» (Deyermond 1995: 27).

32 «En 1931 fue elegido para dirigir la sección de Manuscritos y Ejemplares Raros de la Biblioteca de Cataluña, actividad que también se vería truncada al finalizar la Guerra Civil y que obligó a Bohigas a tener que ingresar en 1941 por oposición en el Cuerpo Facultativo de Archiveros, Bibliotecarios y Arqueólogos, siendo destinado, en primer lugar, a la Biblioteca Provincial y Universitaria de Barcelona y, posteriormente, al Archivo de Hacienda de Palma de Mallorca hasta que en el año 1942 ocupó de nuevo la plaza de jefe de la sección de Manuscritos y Reservados de la Biblioteca de Cataluña» («Pere Bohigas i Balaguer», $D B e$ ). 
sección en $1949^{33}$ y que $c .1953^{34}$ se cuenta ya con 71 obras microfilmadas. En la Memoria 1956 Secció de manuscrits de la Biblioteca de Catalunya se deja constancia de que «la intensificación de los servicios fotográficos y de microfilm y la explotación de los mismos, desde un punto de vista también comercial podría reportar a la Biblioteca beneficios» (pp. 3-4). Son esta fecha y los años siguientes el punto de inflexión para el desarrollo de este servicio en la Biblioteca de Catalunya, por lo que debemos localizar la reproducción de este incunable en época muy cercana, $c$. 1960, de manera que, poco antes de la redacción de la Història de la literatura catalana, si no a partir de la conversación entre Bohigas y Riquer, se habría microfilmado este incunable conservado en la biblioteca privada de algún bibliófilo catalán ${ }^{35}$.

Así nos lo confirman, de hecho, las fichas que, en su día, se hicieron de este microfilm, que no forma parte del catálogo general, al que no ha pasado, según se indica a lápiz en ellas mismas -«No se cataloga»-, ni, lógicamente, se ha incorporado tampoco a ningún tipo de catálogo informático, al no ser fondos estrictos de la Biblioteca de Catalunya ${ }^{36}$, con lo que ello implica para su localización, si bien sí que tuvo un número de inventario (Inv. 706) y una posterior signatura (Microfilm Rotllo B309):

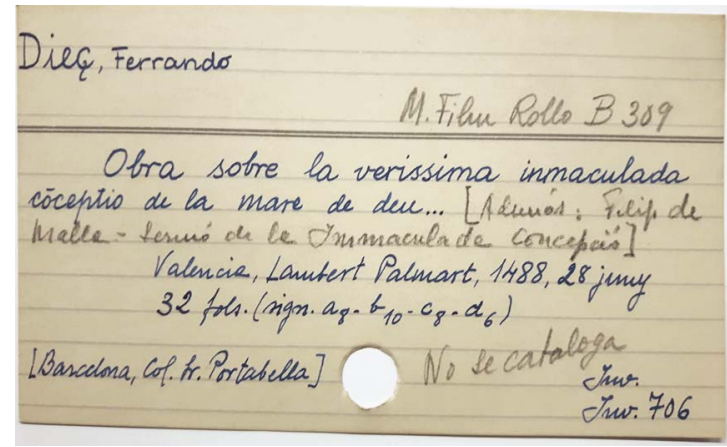

\footnotetext{
${ }^{33}$ «Se instala en abril un aparato lector de microfilms en nuestra sección» (Biblioteca de Catalunya, Capsa 30/4, 1949).

${ }^{34} \mathrm{La}$ carpeta o legajo en cuestión no tiene fecha, pero la Capsa 30/4 de Biblioteca de Catalunya corresponde a la documentación de 1949-1953.

${ }^{35}$ Dudo, por tanto, que Riquer lo consultase directamente, como sugiere Curt Wittlin -«Un exemplar d'aquest incunable havia pogut ésser consultat en casa d'un bibliòfil per Martí de Riquer» (1995: 257)-, especialmente a tenor de lo que advierte en la nota a su Història de la literatura catalana. En esta misma se pronuncia BITECA, sin duda deudora de Wittlin: «El va veure Martí de Riquer a casa d'un bibliòfil i se'n conserva un microfilm a la Biblioteca de Catalunya» (BITECA manid 1451). Desde luego, Riquer sí que conoce su contenido y lo ha leído con detenimiento, como, al menos, nos consta en el caso de la Vesió a la porta de la Senyora Nostra de Gràcia, por lo que el epígrafe en que trata esta obra y, secundariamente, el incunable no dependería de unas notas facilitadas por Bohigas, sino de las que él mismo pudo haber extraído a partir de una reproducción, esto es, del microfilm, que ya estaría fotografiado.

${ }^{36}$ Agradezco a Laia Martí y a Jordi Armengol, de Biblioteca de Catalunya, su generosa respuesta a mis consultas, tanto en términos de información, como por lo que respecta a las fotografías de las fichas manuscritas de este microfilm perdido.
} 


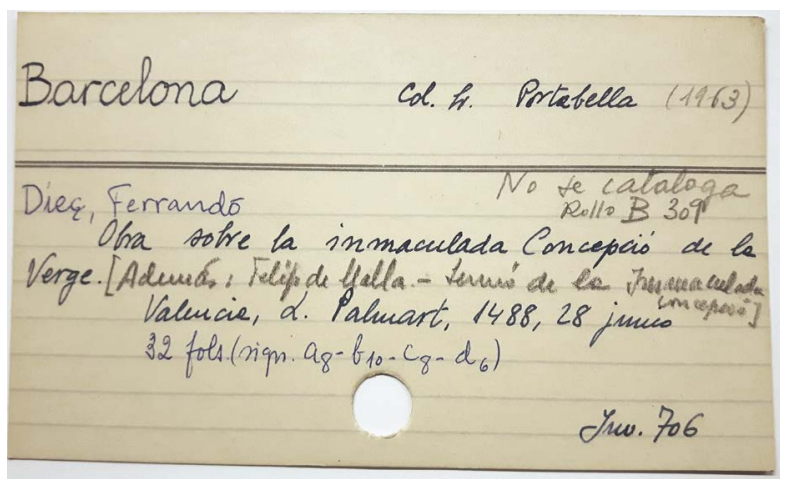

Estas fichas, duplicadas al catalogarse, en sus respectivos cajones del fichero manual de microfilms, por autor y localización, nos proporcionan el título y los contenidos grosso modo, el pie de imprenta, el número de hojas y la estructura colacional de cuadernos, datos todos ellos que se pueden extraer del mero visionado del microfilm, frente a otros que son, a mi parecer, de mayor interés, por su carácter contextual, dado que eran desconocidos hasta ahora. Se trata de la fecha de la reproducción del microfilm, fehacientemente en 1963, lo que confirma mi hipótesis de datación, tal y como se añade a lápiz en una de las dos fichas ${ }^{37}$, al lado de su procedencia, que es, como decía, la biblioteca particular de un bibliófilo catalán a la que pertenecía entonces este ejemplar único: «Barcelona, Col. Sr. Portabella», esto es, la colección barcelonense de Pedro Portabella, en paradero desconocido a día de hoy, cuatro décadas después de su fallecimiento, sobre la cual, a propósito de otro incunable, he estado investigando en los últimos años ${ }^{38}$.

El microfilm se conservaba ya en mal estado a principios del siglo XXI, cuando lo consulté, probablemente por esa antigüedad de la que hablábamos, con fotografías no del todo nítidas y, sobre todo, muy quebradizo, hasta el punto de que las máquinas lectoras actuales lo rompían y quemaban al utilizarlo. Por esa razón, preferí solicitar una reproducción digital, que ayudase a su consulta, conservación y localización, sin tener

${ }^{37}$ En la ficha de localización o procedencia del ejemplar microfilmado, se deja constancia del año en que se produjo la reproducción, aunque se añade con posterioridad y a lápiz. No debió de ser mucho después, porque aún se tenía constancia del dato y, en ese mismo momento, ya se catalogaba como microfilm, pero no como parte del fondo original de la Biblioteca de Catalunya. El número de inventario es el primer paso que se dio sobre el microfilm (Inv. 706), añadido a las fichas con el mismo tono de tinta que los primeros datos de la ficha, lo que habría ocurrido poco después de su llegada a la Biblioteca de Catalunya. En un segundo momento, se le dio la referencia catalogadora actual (M.film. Rollo B309), como demuestra que esta se añadiese después, junto a otra información complementaria, también a lápiz.

${ }^{38}$ Pronto daré noticia de ese incunable también perdido, del que ofreceré, incluso, el texto de su primera y última hoja, conservadas fotográficamente, tal y como ya expliqué públicamente en el proyecto de investigación de mi oposición al cuerpo de Catedráticos de Universidad el 25 de septiembre de 2020. 
que acceder directamente a un microfilm en estado tan precario. O así lo creía, porque, cuando en enero de 2019 me desplacé a la Biblioteca de Catalunya para verlo de nuevo, el microfilm había desaparecido de su caja ${ }^{39}$, quizás por un descuido de ordenación tras una consulta en sala o quizás por un deterioro definitivo, dado su estado. A ello había que sumar, además, que tampoco se conservaba la digitalización que solicité en $2004^{40}$.

Todas estas dificultades y avatares no facilitaron su consulta, ni menos aún su conocimiento por parte de la incunabilística internacional y solo pasó a dos repertorios de obras catalanas ${ }^{41}$ : la Bibliography of Old Catalan Texts del Hispanic Seminar of Medieval Studies de Madison, a cargo de Beatrice J. Concheff (1985: 61, n. ${ }^{\circ}$ 646), que fue el germen de la Bibliografia de Textos Catalans Antics $^{42}$, en el marco del proyecto Philobiblon (BITECA manid 1451). La noticia de este incunable en un catálogo y otro no fueron suficientes para que se incluyese en el Gesamtkatalog der Wiegendrucke (GW), ni en el Incunabula Short Title Catalogue (ISTC), que sí que recogen los otros dos impresos de esta trilogía de Ferrando Díeç sobre la Inmaculada Concepción: el de 1487 (GW 08343; ISTC id00192000) y el de 1489 (GW 08344; ISTC id00192100), en medio de los cuales debería incorporarse este incunable de 1488, con una numeración complementaria que los relacionase.

\section{LA MATERIALIDAD DEL INCUNABLE: MEDIDAS Y METODOLOGÍA ANTE LA PÉRDIDA}

Son muy pocos los rasgos materiales de este incunable que ha destacado la también escasa bibliografía que le ha dedicado atención, lo que, en principio, podría parecer lógico, en ausencia de un ejemplar no conservado, pero, desde luego, la mera existencia de un microfilm aporta más datos que la pérdida absoluta de una edición y es suficiente para poder describir, al menos parcialmente, el impreso. De hecho, Martí de Riquer así lo hace al advertir a partir del microfilm de este incunable que «són 32 folis sense foliar» (1964, III: 280-281, n. ${ }^{\circ}$ 37). No dice más de su materialidad que esta falta de foliación y la extensión total del impreso,

${ }^{39}$ Hacía, al menos dos o tres años, que es la fecha en que recordaban las bibliotecarias de sala que se había advertido la pérdida, ante una solicitud de consulta, por lo que no se podía descartar que pudiese ser anterior.

${ }^{40}$ El 17 de mayo de 2004, concretamente, puesto que conservo la hoja de solicitud, realizada en la propia Biblioteca de Catalunya el día en que también consulté el microfilm. La he puesto a disposición de Biblioteca de Catalunya y, así, esperemos que la vuelva a incorporar a sus fondos, aunque solo se trate de una reproducción, puesto que no deja de ser un incunable perdido y de ahí su interés.

${ }^{41}$ Precisamente por eso, por ser catalanas, no incorporan el impreso de las Orationes ad laudem purissime conceptionis Virginis Marie, de 1489, y, por tanto, no hay ningún repertorio que recoja los tres incunables de esta trilogía inmaculista patrocinada por Ferrando Díeç.

${ }^{42}$ Actualmente, Bibliografia de Textos Antics Catalans, Valencians i Balears. 
ni la bibliografía posterior avanza al respecto, a excepción de BITECA (manid 1451), que añade que es en papel ${ }^{43}$-como es lógico que sea, pero sin datos materiales-, sin duda de buen gramaje, porque así ocurre en los otros dos incunables de esta trilogía de Palmart.

Solo con esto se pueden reconocer las principales líneas de actuación metodológica que utilizaré para la descripción externa de un incunable no conservado más que en fotografías, del que no se ha descrito prácticamente su materialidad: la extracción de datos a partir del análisis del microfilm, algo que parece ser que no se ha hecho directamente ni en Concheff, ni en BITECA ${ }^{44}$, puesto que no avanzan en la descripción material de Riquer; y la reconstrucción de otros que requerirían la manipulación física del original a partir del estudio de los datos de que disponemos mediante el análisis del microfilm tratados en paralelo con los que, fehacientemente, conocemos de los incunables de $1487 \mathrm{y}$ 1489 , con la suerte de que, en fechas muy recientes, se ha recuperado y estudiado la materialidad de este último. Se determinarán tales rasgos materiales en términos de hipótesis, matizados con un circa, como ocurre con las medidas de la tipografía cuando no se dispone de 20 líneas de escritura, si bien la probabilidad de que correspondan o se aproximen mucho a los datos del original es realmente alta, porque parten del análisis real de dos incunables salidos de un mismo taller (1487 y 1489) y formando una cierta unidad editorial, como base para la interpretación de datos parciales de la reproducción fotográfica del microfilm (1488). Especialmente cercanos son, como veremos, los de 1488 y 1489, en ambos casos opúsculos breves en prosa, que debe de ser la razón por la que ya Antoni Ferrando los consideraba productos similares ${ }^{45}$, pero, además de la extensión, hay otras dos características formales que también acercan ambos impresos frente al incunable poético, como el formato y la caja de escritura, con lo que ello implica para la descripción del impreso perdido.

Este incunable sale de las prensas valencianas de Lambert Palmart el 28 de junio de 1488, a instancias de Ferrando Díeç, tal y como nos

${ }^{43}$ «32 fols. Unnumbered» (Concheff 1985: 61, n. ${ }^{\circ} 646$ ). «Es tracta d'un opuscle de 32 folis» (Ferrando 1983: 535). «incunable de 32 folis» (Wittlin 1995: 258). «Writing surface Paper | Leaf Analysis ff.: 32 | Condition folis sense numerar» (BITECA manid 1451).

${ }^{44}$ Como demuestra, en este caso, el mero hecho de que la única revisión que se indica es la de «Martos (2004), Inspecció personal» (BITECA manid 1451), de la que, efectivamente, tenía noticia directa Gemma Avenoza, además de que, como veremos, la descripción interna presenta problemas y esta mediatizada, sin duda, a través de Wittlin 1995. Es evidente que Ferrando (1983) y Wittlin (1995) sí que consultaron el microfilm, aunque sin efectos en cuanto al análisis de la materialidad del incunable, sino para trabajar y editar sus contenidos, ya que este era, en realidad, su objetivo, a diferencia de los dos repertorios bibliográficos catalanes, que contemplaban tanto la descripción interna como la externa.

${ }^{45}$ «El volum que recull les composicions llatines de tots aquests poetes -curiosament molt semblant en característiques i nombre de fulles al del certamen en prosa plana de 1487-» (Ferrando 1983: 560). 
revela su colofón, que ya había transcrito, en su día, Martí de Riquer (1964, III: 280-281, n. 37):

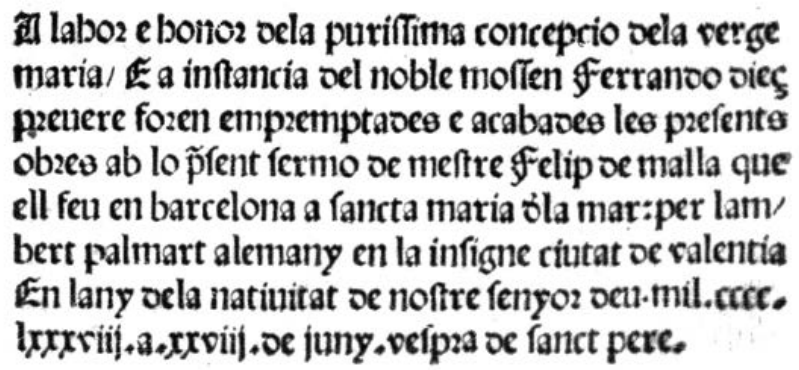

1488, h. d6v

Se trata de un volumen probablemente en papel de un buen gramaje, compuesto por 32 hojas, una extensión similar a la del impreso de prosa latina de 1489, con 26 hojas, frente a las 72 del incunable poético de 1487 . No contiene ni foliación, ni reclamos, aunque sí que cuenta con signaturas de cuaderno en la primera mitad de estos -a excepción del error en el cuaderno $c$, al que falta la ciiij-, localizadas en la esquina inferior derecha, con alfabeto y numeración romana en minúscula. La primera signatura de cada cuaderno solo contiene la letra, aunque no lo he podido comprobar en el primero de ellos, pues la $\mathrm{h}$. a1r falta en la digitalización del microfilm, pero es probable que, en este caso, ni siquiera fuese así, porque habría estado en blanco. De estas signaturas, podemos reconstruir fácilmente, por primera $\mathrm{vez}^{46}$, la estructura material del impreso, cuya colación sinóptica sería, por tanto, la siguiente:

$$
a^{8} b^{10} c^{8} d^{6}
$$

$\mathrm{Su}$ irregularidad, en contraste con los otros dos incunables de la trilogía (a-i ${ }^{8}$ [1487] y $\left.\mathrm{ab}^{8} \mathrm{c}^{10}[1489]\right)^{47}$, y la coincidencia de límites materiales e internos pueden llegar a explicar, de hecho, su génesis, como se explica en otro trabajo ${ }^{48}$.

Lógicamente, al disponer solo de una reproducción, no contamos con datos sobre las filigranas, aunque podría ser un modelo de la mano y la estrella, como en el incunable de $1489^{49}$, con el que presenta otras similitudes, si bien no era así en el de 1487 y el año de distancia entre

${ }^{46}$ En un trabajo bibliográfico, porque sí que la indicaban las fichas manuscritas del catálogo manual de microfilms de Biblioteca de Catalunya.

${ }^{47}$ Véase Martos (2019a: 173) para el impreso de 1487 y Martos (2019d: 83) para el de 1489.

${ }^{48}$ Véase Martos, en prensa.

49 «Todas las filigranas responden al modelo de la mano, pero con diseños diferentes, aun siendo todas manos enguantadas» (Martos 2019d: 86). 
ambos impresos es suficiente para pensar en remesas de papel diferente. Es por ello que no podemos intentar reconstruir la estructura material de cada uno de los cuadernos, en cuanto a plegado e imposición, ni siquiera aventurarnos a hipótesis alguna, porque el incunable de 1489 demuestra que Palmart no era regular al respecto. Es más que probable que los pliegos $a$ y $c$ sean conjugados, con una estructura tradicional, pero no podemos asegurar que la formación de los pliegos $b$ y $d$, que requerirían medios pliegos, colocaran estos en el interior del cuaderno, ni siquiera que fuera uno solo en cada uno de ellos, a la luz de la praxis en la edición de las Orationes ad laudem purissimi conceptionis Virginis Marie ${ }^{50}$.

La caja de escritura, a línea tirada, está compuesta de 28 líneas $^{51}$, muy regularmente, a excepción del momento en que se produce un cambio de obras, que deja líneas en blanco al final (h. a5v, b5r y b10v) para comenzar la nueva pieza en la hoja siguiente; o de los paratextos editoriales -rúbrica inicial (h. alv) o colofón (h. d6v)-y, entre ellos, las rúbricas, tanto de obras (h. a2r, b1v, b2r-v, b3r, b4r-v y b5r), como las finales de autoría (h. a1v) $)^{52}$, con espacios de cortesía, antes y/o después, que no las aglutine con el texto; $\mathrm{o}$, incluso, se desplaza el nuevo párrafo a la hoja siguiente si solo hay capacidad para una línea (h. b8v) ${ }^{53}$, si no es que, simplemente, se respeta un cambio de párrafo o epígrafe, puesto que esto ocurre en dos ocasiones más también en la obra ganadora, de Bartomeu Dimas (h. b6r y b7v), en los tres casos ocupando 27 líneas de escritura y dejando una en blanco. En todas las hojas, sin embargo, si se computan las líneas en blanco, contamos con una caja muy regular, de un mismo pautado: 28 en total.

No es baladí que la caja de escritura coincida en número de líneas en este impreso de 1488 y en el de las Orationes de 1489, frente al cancionero incunable de 1487, que tendría 25 líneas: lo justificaría una coincidencia en el formato de plegado de los primeros, en $4^{\circ}$ y no en $8^{\circ}$, como este último. A simple vista, ya se observan diferencias entre la caja de escritura del más antiguo de estos incunables, respecto de los

\footnotetext{
${ }^{50}$ «Los cuadernos $a$ y $b$, formados por dos pliegos conjugados y con solaridad entre los bifolios a2-a7, a3-a6, b2-b7 y b4-b5, a la luz de las filigranas, presentan una estructura regular y previsible. No queda tan claro, sin embargo, el modelo de composición del cuaderno $c$, que no parece responder al esquema de dos pliegos conjugados y medio pliego central, sino a alguna solución más compleja. Como confirma la continuidad de la filigrana, las hojas c4-c7 presentan solidaridad y el hecho de que el bifolio c5-c6 sea el único de este cuaderno que no tiene marca de agua parece apuntar a que ambos pertenecen a un mismo pliego. Este estaría en la posición interna del cuaderno y lo enmarcarían tres medios pliegos exteriores (c1-c10, c2-c9 y c3-c8), todos ellos con filigrana, lo que no permite otro esquema: una estructura de cuaderno, por tanto, muy interesante por infrecuente» (Martos 2019d: 86).

${ }^{51}$ Comprobadas en las hs. a2v-a5r, que no presentan líneas en blanco. La signatura de cuaderno, como es lógico, no computa en ningún caso en el número de líneas.

${ }^{52}$ En este caso, solo en una ocasión, pero es un recurso tipográfico muy frecuente en el impreso de 1487.

${ }^{53}$ Por ello, la se remata solo con 27 líneas y una final en blanco.
} 
dos en prosa y, de hecho, un mero ejercicio de cómputo de las grafías y espacios de cada línea así lo ratifica. Más allá de que es cierto que cada tipo tendría diferencias de tamaño, al aplicarlo a un total de cinco líneas, las primeras completas de cada impreso con una misma tipografía ${ }^{54}$, se genera un efecto de probabilidad que, a mi parecer, hace evidentes los resultados:

\begin{tabular}{|l|c|c|c|}
\cline { 2 - 4 } \multicolumn{1}{c|}{} & 1487 & 1488 & 1489 \\
\hline CÓMPUTO DE GRAFÍAS & 41 & 51 & 52 \\
Y ESPACIOS DE CINCO & 41 & 52 & 51 \\
LÍNEAS DE ESCRITURA & 39 & 52 & 49 \\
& 44 & 54 & 54 \\
& 45 & 55 & 53 \\
\hline
\end{tabular}

La horquilla del incunable poético (39-45) contrasta con las propias de las ediciones de prosa en romance (51-55) y latina $(49-54)^{55}$, lo que, junto al número de líneas y la mera apreciación visual, demuestra que estos últimos comparten un mismo formato in $4^{\circ}$, con lo que los corondeles del papel son horizontales, de manera que la filigrana se encontraría en el plegado, en el centro de algunos de los bifolios resultantes y, por ello, en el cosido del volumen, que se llega a apreciar en las fotografías del ejemplar.

Las diferencias en el formato tienen repercusiones, por tanto, en las medidas de la caja de escritura, de $130 \times 76 \mathrm{~mm}$ en el incunable de 1487 frente a los 146 x $91 \mathrm{~mm}$ del impreso de 1489, por lo que, dadas las similitudes, podríamos aceptar esta última, a manera solo aproximativa, para la edición perdida de 1488. De la misma manera, las diferencias en el plegado generan un menor tamaño del incunable poético, cuyo papel debió de tener un mínimo de 166 x $118 \mathrm{~mm}$, frente a los 215 x $152 \mathrm{~mm}$ del impreso en prosa latina. De todo ello, podríamos extrapolar que el incunable de 1488 tuvo una caja de escritura de $c .146$ x $91 \mathrm{~mm}$ y que su papel llegó a alcanzar c. 215 x $152 \mathrm{~mm}$.

Tal aproximación, suficientemente válida en tales términos, aún se podría afinar más a pesar de la imposibilidad de comprobar físicamente sus medidas, por la pérdida material del incunable, recurriendo a un ámbito interdisciplinar como el de las humanidades digitales. Sería posible a través de la herramienta de transparencia y opacidad de un programa de tratamiento de imágenes, que permite hacer visible porcentualmente las fotografías subyacentes o, lo que es lo mismo, hacer parcialmente

${ }^{54}$ Porque el de 1487 tiene, como veremos, dos tipografías y la línia 1 de la h. a1v las combina, de manera que se han computado las líneas 2-6.

${ }_{55}$ «Debió de ser, sin duda, su contenido lo que determinó su formato, no solo por la mayor manejabilidad de un impreso poético, sino por el aprovechamiento del papel, dado que el verso reducía la caja de escritura notablemente» (Martos 2019d: 88). 
transparentes las imágenes o capas superiores, con lo que los trazos de escritura se superponen. Si así lo hacemos a partir de una grafía concreta, especialmente de una mayúscula, o de un grupo de grafías o palabra coincidente, consiguiendo el mismo tamaño de ambas, obtendremos una medida proporcional entre ambos impresos.

Para ello, nos hemos encontrado ${ }^{56}$ con dos circunstancias que había que salvar. Por un lado, convenía localizar en una situación similar de la hoja esa grafía o secuencia gráfica en ambos impresos, al menos en una misma línea y preferiblemente si esta era la primera, la última o alguna relativamente central, para que no se produjese un desplazamiento excesivo de ambas cajas de escritura ${ }^{57}$. Esta circunstancia se daba en la primera línea de la h. c7v del impreso de 1488 y de la h. c3v del de 1489, que contienen, respectivamente, las palabras Quia y Quid. En ambos casos disponemos, por tanto, de una secuencia con una letra mayúscula y dos minúsculas más, que nos ha permitido una superposición de imágenes muy afinada, como veremos. Por otro lado, las imágenes tenían una muy ligera deformidad, casi imperceptible ${ }^{58}$, generada por la perspectiva fotográfica y por la curvatura de las hojas abiertas de un libro, que, en cualquier caso, debía ser corregida para el éxito del ejercicio. Para esto último, se ha trabajado primero de manera independiente con las hojas seleccionadas de ambos incunables, aplicando unas guías alrededor de las respectivas cajas de escritura, ajustándolas para que no se perdiesen las proporciones y corrigiendo la imagen para obtener una perspectiva plana $^{59}$.

${ }^{56}$ El plural no es de modestia, sino que incluye a Enrique Ripoll, que ha sido crucial para esta investigación en cuanto a los aspectos técnicos informáticos que aquí describo, a quien le agradezco su generosa dedicación.

${ }^{57}$ Lo que, en otra localización, no habría sido un problema grave, sino que habría requerido tomar más medidas de las cajas para establecer su tamaño.

${ }^{58}$ Mucho menor, lógicamente, que la del Cançoner de Mayans, al que se le aplicó este método para estudiar una obra perdida (Martos 2016c: 195-196), un extenso manuscrito cuyos límites contrastan con estos breves opúsculos, que contaban con una obertura casi plana.

${ }^{59}$ Podría ser que afectase a algún píxel concreto en grafías aisladas, disminuyéndola o agrandándola ligeramente, pero esto sería muy puntual y no tendría consecuencias en la proporción total de las medidas. 
matrimonic la aía creaoa per oeu feng percat. Duia oetie non eft actor mali culpe bagen en fi peceat origi nal/eg aci afpeculaz ã generacio co acte ơ natura en lo

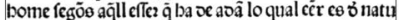
ra lapfa c cousuptep peccat/ car abam ane oel peccat no engenosa caz fi bo baguce no fora flat aquell fill cō cebut en pecrat oziginal ne los fille oc aquell $c$ acte oe generacio no es en lo bome fegöos cfier $\delta$ gुra/oon app q̀ bome batejat no engenoza fino fegong ce cfter oe na tura: q̃ eft vio infita rebuo ex fimilib" filium percano

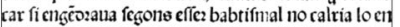
Gcosat effer batejat. oon appar que engenosa ab lo se fallinçt ofla iufticia osiginal la puacio ocla qual $\mathfrak{e}$ im putaoa a culpa mas lo oit peccat ce lasoncberom ia anima ce röiütcta ab tal roze fene aquell onamét ocla osiginal iufticia e tota carn bumanal pgeneracio oiri uasa ba aquclla innata puacio e rebclio inouctiva en la aîa oe peccat per aälla comixtio axi cō liquoz tona paen p infecte verell infectio: oon couc oir que lo pee cat osiginal es en lo cors caufalmêt c enl la aia formal ment $\mathrm{c}$ fubicctiuamèt: axi com la malaltia ce cn la ri anoa infecta caufalment e es en lo co2s a limentat fub iectimament $/ e$ aqueft pectat no co tolt fi no pracia la qual fi no reftituce iufticia original tol la obligacio of bauer aquel lasoon ce que lo oit peccat zomant tant cö en la pena miae noen la culpa:e ba ocu iftetuit que tor oefallimét ó iufticia origunal fra bagut $p$ culpable c per pecrat osiginal cntro fus que per gracia babtifmal ce

1488, h. c7v

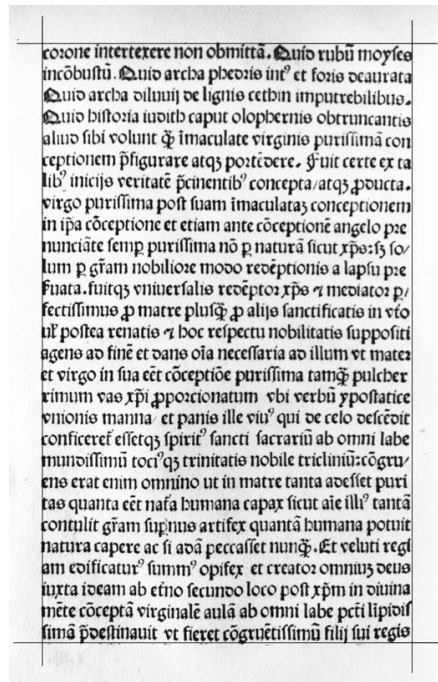

1489 , h. c3v

Al disponer de los datos exactos del incunable de 1489, si la coincidencia de las medidas de la caja, tras ajustar la escala a partir de la superposición no fuese completa o razonablemente coincidente, se podrían extraer unos datos aproximados con unas simples reglas de tres, que considerasen las medidas del impreso conservado y las de su imagen fotográfica, para después aplicar una nueva operación de este resultado en relación con la imagen digitalizada del incunable perdido. Incluso recurriendo a estas operaciones matemáticas ${ }^{60}$, se podría hilar muy fino en cuanto a las medidas de la caja de escritura y, por extensión, de las veinte líneas a partir de las cuales establecer la tipografía de este impreso. La superposición de ambas imágenes, tras haberlas hecho coincidir a una misma escala a partir de la secuencia Qui y habiéndole aplicado la herramienta de transparencia y opacidad, nos ofrece unos resultados evidentes en cuanto a la coincidencia de la caja de escritura entre ambos impresos ${ }^{61}$ y, por ello, es razonable asumir, ante la ausencia de un ejemplar físico, que sus medidas eran, efectivamente, de $c .146$ x $91 \mathrm{~mm}$, lo que se podrá hacer extensivo a otros datos materiales similares ${ }^{62}$ :

${ }^{60}$ En este caso, como se preveía, no ha sido necesario recurrir a ellas.

${ }^{61}$ Comprobados en otras hojas del impreso digitalizado, especialmente seleccionadas aquellas sin cambio de perspectiva por la abertura del libro, pero sin amplias secuencias de grafías, usando algunas sueltas y aplicándole la guía de la caja de escritura, que encajaba de manera perfecta.

${ }^{62}$ Como las veinte líneas para la medida tipográfica e, incluso, las medidas mínimas del papel, aunque estas últimas no sean determinantes en una obra impresa. 


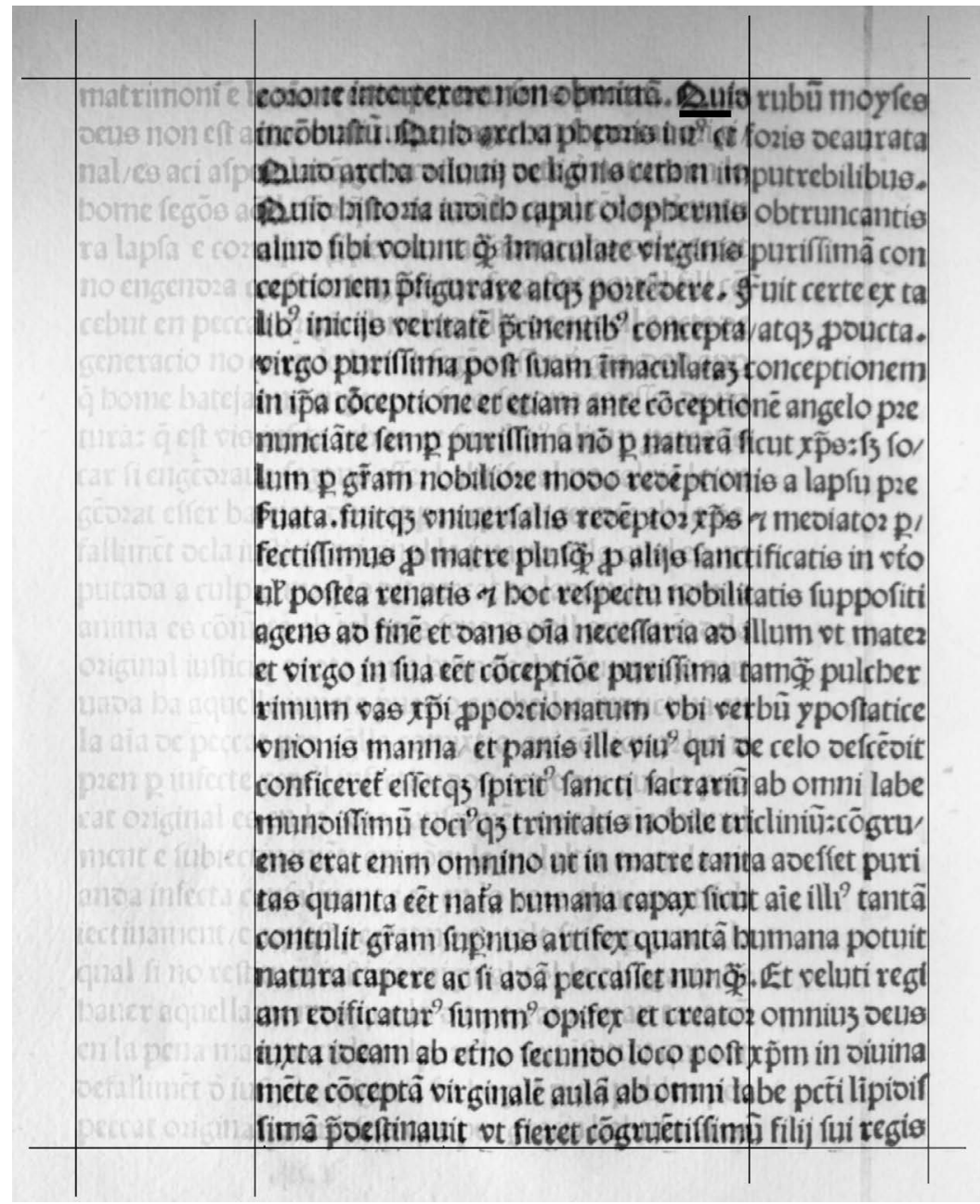

Superposición con transparencia de las hojas c7v (1488) y c3v (1489)

LA MATERIALIDAD DEL INCUNABLE: TIPOGRAFÍA(S)

El microfilm es suficiente para comprobar que la letra es gótica, cuyo $^{63}$ modelo de $M$ coincide con el de los otros impresos de esta trilogía de Lambert Palmart, patrocinada por Ferrando Díeç. No encontramos este diseño entre los ofrecidos por Haebler, aunque el más parecido es M51, de rasgos puntiagudos frente a un mayor redondeamiento del modelo de estos impresos de Palmart. Así lo había advertido ya el $T y$ penrepertorium der Wiegendrucke (TW), al referirse a él como «ähnlich

${ }^{63}$ De la tipografía más usada en este incunable, pues, como veremos, cuenta con dos, a diferencia de los de 1487 y 1489. 
M51» ('similar a M51'), para catalogarlo como M16B, correspondiente a la tipografía que identifica como ma12185, esto es, el tipo 3:104/105G de Lambert Palmart según el Gesamtkatalog der Wiegendrucke ${ }^{64}$.

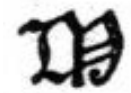

M51-Haebler

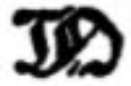

M16B-TW

De esta trilogía, el GW solo atribuye esta tipografía concreta al incunable poético de 1487 (GW 08343), pero no al de 1489 (GW 08344), del que se limita a indicar, simplemente, que es gótica, y, como es lógico, tampoco dice nada del que aquí se estudia, de 1488, porque no lo incluye. No obstante, este catálogo documenta el tipo 3:104/105G de Lambert Palmart en nueve incunables salidos de su taller ${ }^{65}$, en un arco temporal que va desde 1482 hasta $1492^{66}$. A estos nueve habría que añadir, por tanto, otros dos: los incunables de 1488 y 1489 , pues toda la trilogía se imprime con esta tipografía, cuya medida de veinte líneas es de $104 \mathrm{~mm}$ en los dos incunables conservados, según he podido comprobar físicamente sobre los originales, como también habría que concluir para el impreso perdido a la luz de los datos que nos ha ofrecido su tratamiento digital.

Ahora bien, este incunable tiene una importante peculiaridad tipográfica que lo singulariza frente a los otros dos de la trilogía, ya que en las h. a1v-a2r utiliza unos tipos de mayor tamaño ${ }^{67}$ para los íncipits de la extensa rúbrica inicial, así como del Llibell y del Introit de Ferrando Díeç: en el primer caso, en media línea; en el segundo en una línea completa; $y$ en el tercero en dos líneas.

El incunable de 1488 utiliza esta tipografía de mayor formato también en la segunda de las características invocaciones verbales que

${ }^{64}$ La define Salvà como «letra gótica mui clara, por ser poco angulosa y bastante gruesa» (1872: 1, 141, n. $\left.{ }^{\circ} 301\right)$. Por esta definición, duda Haebler (1903-1917, r: 105, n. ${ }^{\circ} 228$ ), en un principio, de que el modelo tipográfico de esta letra sea el habitual de Palmart, aunque cambia de opinión tras localizar y estudiar Ernst el incunable de 1487 conservado en la Biblioteca Universitària de Barcelona, de cuyos datos concluye Haebler que «es la letra común de texto, que Palmart empleó para todos sus libros en gótico» (1903-1917, II: 63, n. ${ }^{\circ} 228$ ).

${ }^{65}$ Catorce me indica Fermín de los Reyes que ha localizado para su repertorio de incunables hispánicos, además de uno sin ejemplar conservado, por lo que el arco temporal se ampliaría ligeramente.

${ }^{66}$ Son los impresos que el Gesamtkatalog der Wiegendrucke registra como GW 00057 , $0005710 \mathrm{~N}, 00060,00061,0125950 \mathrm{~N}, 08343,10428,10430$ y M10417.

${ }^{67}$ Romero Lucas atribuía al incunable de 1489, del que desconocía el ejemplar, porque no obtuvo reproducción, una «Letra gótica de [2 tamaños]. [Tamaño grande. Gótica-4: 140-G]. Tamaño pequeño. Gótica-3: 104G. A línea tirada» (Lucas 2005, II: 129-130, n. $\left.{ }^{\circ} 25\right)$. Sorprende que le suponga erróneamente una doble tipografía, de dos tamaños, porque este es, en realidad, un rasgo del incunable en prosa vulgar de 1488, que no cataloga y, por tanto, desconoce, como el GW y el ISTC. De hecho, ni siquiera la letrería de tamaño mayor coincide en este incunable, como veremos, con la tipografía que aquí atribuye al impreso de 1489 . 
preceden a los textos de Ferrando Díeç en esta trilogía, Jhesus, Marie filius, la primera de las cuales de este impreso (h. alv) presenta los tipos de menor tamaño, del cuerpo del texto y de los otros dos incunables (Palmart 3:104/105G), y se introduce a manera de titulillo, en una posición que parece que afecta a todo el incunable -si no es que hay que atribuir la extensa rúbrica inicial a este editor. Sin embargo, la segunda, que encabeza la h. a2r, precediendo a la rúbrica y al texto del Introit, presenta la tipografía mayor, con la suerte de que incluye una $M$ mayúscula:

\title{
Jerus EAgarie filius.
}

\author{
En bonoz bela mare oe ocu forn \\ oela fua purifima conceptio in \\ troit del Donados oe joya en p:o \\ ra plana.
}

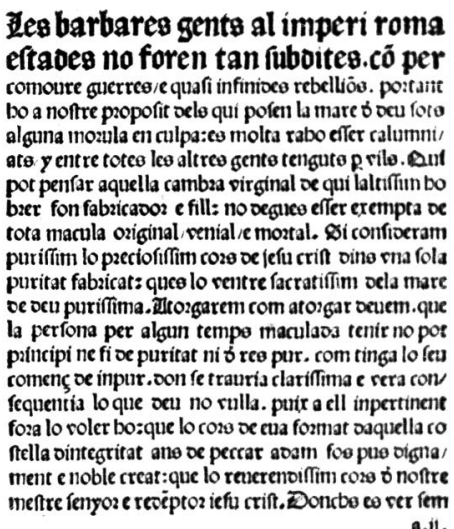
meftre fenpos e receptos iefu crift. Dontbe co rer fem

a.11.

1488, h. a2r

Se trata de la M50F de Haebler, que el Gesamtkatalog der Wiegendrucke identifica con la tipografía 2:142G de Lambert Palmart y que el Typenrepertorium der Wiegendrucke cataloga como ma12184, documentada aquí en otros dos incunables de este mismo impresor de datación cercana: los Furs de València (GW M10428) ${ }^{68}$ y el pliego suelto de la Sentència donada per lo rey en Jacme sobre los delmes e primícies del regne de Valèntia (GW M10417) ${ }^{69}$. Ambos presentan la misma

${ }^{68}$ En este caso de mayor formato, in folio, y a doble columna.

${ }^{69}$ Aunque el Gesamtkatalog der Wiegendrucke le atribuye un formato in $4^{\circ}$ (GW M10417) y no he podido comprobarlo materialmente aún, por la disposición de corondeles, la caja de escritura es similar a la del incunable poético de esta trilogía, que es in $8^{\circ}$. Estando en pruebas este artículo, me informa Fermín de los Reyes que hasta 12 de los 14 incunables góticos de Palmart con ejemplar conservado que incluye en su repertorio de incunables valencianos presentan también esta tipografía mayor. Esto supone, por tanto, que solo los otros dos incunables de esta trilogía no tenían la tipografía 2:142G; ergo, lo que parecía una singularidad del impreso de 1488 era, en realidad, una constante del taller de Palmart, mientras que los impresos de 1487 y 1489 se apartaban de la norma. 
combinación de tipos que el impreso objeto de este trabajo, con el mismo uso de esta tipografía mayor, para íncipits de textos y paratextos, especialmente similar en el último de ellos, impreso en fecha muy cercana, el 10 de septiembre de 1487:

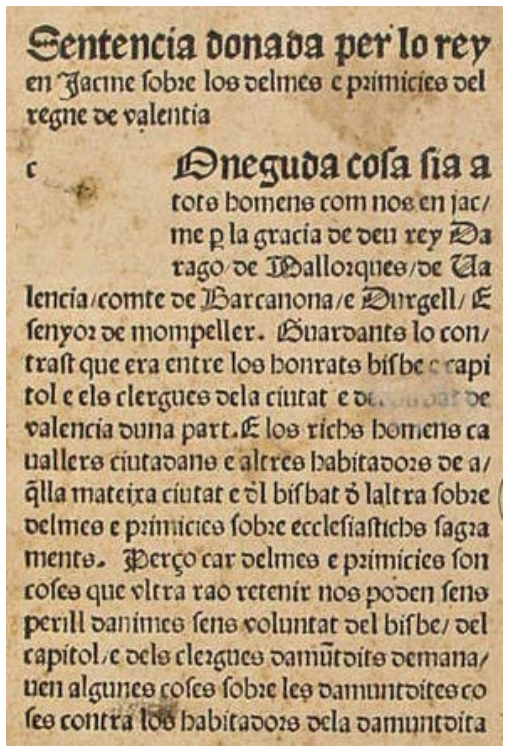

h. $1 \mathrm{r}$ per la onituerfitat oe murueose. En ßSuilla mo ftrany/e en Østmo vinaoer per la vnituez fitat oe algejira. En Sancbo oanoilla en Iltrnau vinaoer per la vniuerfitat oe Liria. En एБuillem oe gerona/e en IDerenguer oe clara per la oniuerfitat oe Denia. En LSuil lem oe verous/ e en JBernat pallates per la vniuerfitat ở Bastroia. E molto oaltreopie fents. Eencara J/2albert oalauanya meftre en leyg/Jgeftre LSil oe lopiyen artiacba oe terol/ e en Jacme grony ciutaoa oe IBarca nona. E moltes oaltree oel cōfell oel fenços xcy.

\section{Aci feneix la fentencia oona}

oa per lo rey en Jacme oc bona menozia fobre los oelmes e paimicies ocl regne ob va lentia. Ia qual fententia a inftantia oel bon rat en đIntboni oe fpi lauraoo2 e correooz Dozella es ftaoa empremptaoa en la infigna ciutat oe valentia p Lambert palmart ale/ many. Lo seen via se fetembze.

\section{.Any mil.ccce.lxxxvij.}

\section{h. $8 \mathrm{r}$}

LA MATERIALIDAD DEL INCUNABLE: IMPOSICIÓN Y ORIGINAL(ES) DE IMPRENTA

No sabemos si, como en el incunable poético de 1487, se había usado también tinta roja, además de la negra, pero es muy probable que, si se hizo, se limitó a la extensa rúbrica inicial, como en aquel caso, aunque es cierto que, en la reproducción fotográfica, en blanco y negro, no se observa ninguna escala de grises que pueda apuntar a ello. Es muy probable, por tanto, que esta función decorativa, que ya se abandonó en el incunable en prosa latina, viniese a cumplirla en este impreso de 1488 la tipografía mayor de estos íncipits, dado que, de igual manera, se limita, como en el cancionero que abría la trilogía, al principio de la edición.

En este mismo sentido hay que entender la diferente praxis de los tres incunables en cuanto a su inicio.

El impreso de 1487 debía de tener una hoja completa de inicio, probablemente en blanco (h. a1) -perdida en los dos ejemplares conservados-, porque el texto y la rúbrica inicial en tinta roja comienza en la h. a2r:

El texto del impreso de 1488 empieza en la h. alv, por lo que es muy probable que la h. alr estuviese en blanco, más aun teniendo en cuenta que no pudo haberse perdido, ya que solo estamos hablando del recto y no 
de una hoja completa. El mero hecho de no incluirse en la reproducción ya demuestra que debía de estar en blanco. Esta es la razón por la que en enero de 2019 me desplacé a la Biblioteca de Catalunya a consultar el microfilm, a pesar de disponer de su digitalización, ya que esta comienza en la h. alv $\mathrm{v}^{70}$, pero eso no implicaba que también lo hiciera el microfilm, sino que la hoja en cuestión podría haber estado en blanco y el servicio de reprografía no haberla incorporado, por ello, al hacer la copia digital ${ }^{71}$. Dado que el microfilm estaba extraviado, no lo pude confirmar, pero, si hubiese tenido texto originalmente la $\mathrm{h}$. a1r, no habría tenido sentido que en el microfilm antiguo, efectuado a partir del original entonces perteneciente a Pedro Portabella, no se hubiese incorporado su reproducción.

Finalmente, el incunable de 1489 no presenta ningún formato de portada y su texto comienza directamente en la h. alr, con una rúbrica inicial con idéntica tipografía a la del libellum, razón por la cual, a pesar de estar separadas ambas por una línea en blanco, Gallardo debió de aglutinarlas en su descripción. Esta solución es, en esencia, muy similar en cuanto a contenidos en toda la trilogía, iniciada por la rúbrica contextualizadora de la obra, a manera de paratexto editorial y seguida de los paratextos del certamen, fundamentalmente del llibell. Esto confirmaría una cierta unidad editorial en cuanto a la composición de la primera hoja, en función de portada o inicio, de lo que, a su vez, se derivaría que la h. alr-v de 1487 estaría completamente en blanco, mientras que el incunable de 1488 dejaría así solo el recto, para comenzar el impreso en la h. alv, una peculiaridad que lo caracteriza y que Palmart abandona en la edición de 1489.

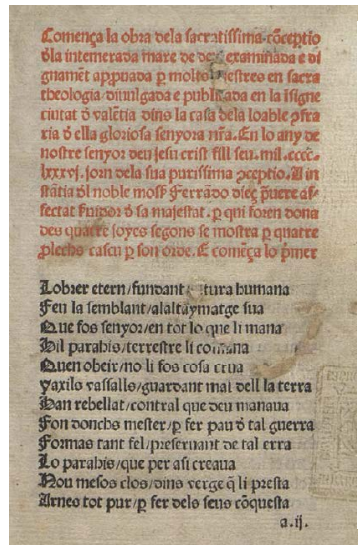

1487, h. a2r

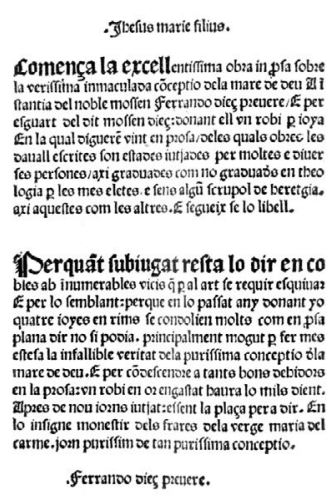

1488, h. alv

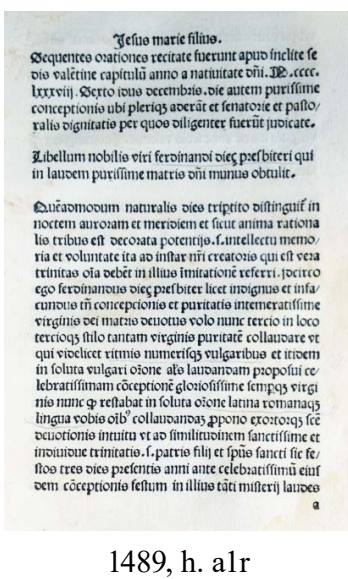

1489, h. alr

${ }^{70}$ Y, por esta razón, no sabemos aquí nada sobre la encuadernación del ejemplar, a diferencia de los otros conservados de esta trilogía de incunables.

${ }^{71}$ De mi consulta de 2004, recuerdo que había una importante extensión de rollo sin fotografiar, pero no si las hojas en blanco del incunable estaban también reproducidas; en cualquier caso, tengo razones para pensar que así era, como explicaré en otro trabajo, para no desarrollar aquí otros argumentos que lo justifican y que ahora supondrían una digresión importante. 
De la imposición de los diferentes contenidos en este incunable destaca, asimismo, la diferente práctica en cuanto a los textos de Joan Roís de Corella y de Bartomeu Dimas, respectivamente, puesto que tal circunstancia parece apuntar al mantenimiento de un rasgo del original de imprenta $-u$ originales - que no tengo la menor duda de que dejan entrever rasgos del autor. La obra de Joan Roís de Corella es la única que contiene rúbricas internas, que organizan sus piezas distribuyendo los contenidos en epígrafes sin párrafos, algo que caracteriza buena parte de las obras de este autor y que, por tanto, no habría que atribuir a un copista, ni menos aún a un componedor o cajista, sino que parece ser un rasgo del autor, con lo que ello implica para la interpretación de estos paratextos en su producción.

Por otro lado, el original de la obra de Bartomeu Dimas, que no tiene estas rúbricas internas, sí que se debía de dividir en epígrafes o párrafos, puesto que de esto queda huella en la edición, a diferencia de lo que ocurre con los textos de Ferrando Díeç y de Felip de Malla, que son un continuum en prosa. Además de las líneas en blanco que marcan esta circunstancia en tres ocasiones del texto de Dimas, a las que me he referido anteriormente al hablar de la caja de escritura, hay también cambio de epígrafe y párrafo en las h. b7r y b10r, aunque aquí solo se evidencia mediante una última línea de párrafo incompleta y la mayúscula inicial del nuevo epígrafe. Esto podría responder, como sugería al hablar de originales de imprenta, a pequeños cuadernillos independientes que funcionaron como tales para las cuatro secciones del incunable, si no es que se respetaron con ese grado de minuciosidad las copias proporcionadas por los autores a la hora de formar una hipotética copia unitaria.

El estudio interno de este incunable, así como la interacción entre contenidos y materialidad, requieren mayor atención que un epígrafe y, por tanto, la recibirá en otro trabajo, si se me permite recurrir al tópico cierto de los límites de este. Aquí queda, de momento, el primer estudio externo de un incunable perdido, algunos de cuyos rasgos son peculiares dentro de la trilogía valenciana impresa por Palmart, mientras que otros ayudan a entenderla. Sea este un revulsivo para su incorporación a los repertorios de incunabilística y, sobre todo, sirva para mantener su noticia, puesto que, con la pérdida del microfilm, se avanzaba hacia el olvido. $\mathrm{O}$, mejor si cabe, convierta este incunable en un ítem de una lista de compras, como definía Deyermond los catálogos de literatura perdida ${ }^{72}$, a partir de la cual continuar su búsqueda y que, de esta manera, pronto se pueda ofrecer la noticia de su recuperación

${ }^{72}$ Que conllevan «la finalidad práctica de proporcionar una "lista de compras" para que los hispanomedievalistas sepan, al encontrar en una biblioteca o un archivo una obra que no conocen, si se trata de una obra que se creía perdida» (Deyermond 1995: 19). 


\section{REFERENCIAS BIBLIOGRÁFICAS}

Aguiló I Fuster, Marià (1923), Catálogo de obras en lengua catalana impresas desde 1474 hasta 1860. Madrid: Sucesores de Rivadeneyra.

Antonio, Nicolás (1788), Bibliotheca Hispana Vetus, sive Hispani scriptores qui ab Octaviani Augusti aevo ad annum Christi MD floruerunt. 2. ${ }^{\text {a }}$ ed. Madrid: Apud Viduam et Heredes D. Joachimi Ibarrae Regii Quondam Typographi, 2 vols. [1. ${ }^{\mathrm{a}}$ ed.: 1696].

Arnoult, Jean-Marie (1979), Catalogues régionaux des incunables des bibliothèques publiques de France, I. Bibliothèques de la Région Champagne-Ardenne. Bordeaux: Societé des Bibliophiles de Guyenne.

Askins, Arthur L.-F. (1988), «Muestrario de incunables hispánicos extraviados de la Biblioteca Colombina», en María Luisa López-Vidriero y Pedro M. Cátedra (eds.), El libro antiguo español. Actas del Primer Coloquio Internacional (Madrid, 18 al 20 de diciembre de 1986). Salamanca: Ediciones Universidad de Salamanca/Biblioteca Nacional de España/Sociedad Española de Historia del Libro, pp. 37-53.

[BITECA] Beltran, Vicenç et alii (coords.), Bibliografia de Textos Antics Catalans, Valencians i Balears, en Philobiblon. Berkeley: The Bancroft Library - University of California Berkeley. En línea: $<$ http://sunsite.berkeley.edu/Philobiblon/phhmbi.html $>$ [consulta: 06/07/2021].

Blázquez Fraile, Agustín (1945), Incunables de la Biblioteca Universitària. Barcelona: Universitat de Barcelona.

BRunet, Jacques Charles (1861), Manuel du libraire et de et de l'amateur de livres, 2. Paris: Librairie de Firmin Didot Frères, Fils et C. DOI: https://doi.org/10.1093/nq/s2-XII.304.340a.

CERdÁ y Rico, Francisco (1778), «Notas al Canto del Turia», en Gaspar Gil Polo, La Diana enamorada, cinco libros que prosiguen los VII de Jorge de Montemayor. Madrid: Imprenta de don Antonio de Sancha, pp. 267-523.

ConchefF, Beatrice Jorgensen (1985), Bibliography of Old Catalan Texts. Madison: Hispanic Seminar of Medieval Studies.

CopInger, Walter A. (1895-1902), Supplement to Hain's Repertorium Bibliographicum in Two Parts, 3 vols. London: Henry Sotheran and Co. [DBe] Diccionario Biográfico electrónico, Real Academia de la Historia. En línea: <https://dbe.rah.es/biografias/49285/pere-bohigas-i-balaguer> [consulta: 27/08/2021].

DeYERMOND, Alan (1995), La literatura perdida de la Edad Media castellana: catálogo y estudio, I: épica y romances. Salamanca: Universidad de Salamanca («Obras de Referencia», 7).

Dutton, Brian y Jineen Krogstad (1990-1991), El cancionero del siglo XV (c. 1360-1520), 7 vols. Salamanca: Universidad de Salamanca («Biblioteca Española del Siglo XV»). 
FERrANDo Francés, Antoni (1983), Els certàmens poètics valencians. Valencia: Institució Alfons el Magnànim.

FERRER y Bigné, Rafael (1873), Estudio histórico-crítico sobre los poetas valencianos de los siglos XIII, XIV y XV. Valencia: Imprenta de José Rius.

Forteza Oliver, Miquela (2011), Los origenes de la imprenta en Mallorca. Palma: Objeto Perdido Ediciones.

FUSTER, Justo Pastor (1827), Biblioteca valenciana de los escritores que florecieron hasta nuestros días, con adiciones y enmiendas a la de D. Vicente Ximeno. Valencia: Imprenta y Librería de José Ximeno.

Gallardo, Bartolomé José (1863-1889), Ensayo de una biblioteca española de libros raros y curiosos, 4 vols. Madrid: Imprenta y Estereotipia de M. Rivadeneyra/Imprenta y Fundición de Manuel Tello.

García Craviotto, Francisco (1989-1990), Catálogo general de incunables en bibliotecas españolas, 2 vols. Madrid: Ministerio de Cultura/ Dirección General del Libro y Bibliotecas.

GoFf, Frederick R. (1973), Incunabula in American Libraries. A Third Census of Fifteenth-Century Books Recorded in North American Collections. Millwood, NY: Kraus Reprint Co.

GuIX, José María (1954), «La Inmaculada y los reyes de Aragón en la Baja Edad Media», Miscellanea Comillas, 22, pp 193-326.

[GW] Gesamtkatalog der Wiegendrucke, Leipzig: K. V. Hiersemann. En línea: <http://www.gesamtkatalogderwiegendrucke.de/> [consulta: 15/06/2021].

Haebler, Konrad (1897), The Early Printers of Spain and Portugal. Londres: Bibliographical Society at the Chiswick Press.

HAEBLER, Konrad (1903-1917), Bibliografía ibérica del siglo XV. Enumeración de todos los libros impresos en España y Portugal hasta el año de 1500. La Haya/Leipzig: Martinus Nijhoff/Karl W. Hiersemann, 2 vols. [Reimpresión facsímil en Madrid: Julio Ollero, 1992].

HaIn, Ludovico (1826-1838), Repertorium bibliographicum, in quo libri omnes ab arte typographica inventa usque ad annum MD, tipys expressi ordine alphabetico vel simpliciter enumerantur vel adcuratius recensentur, 4 vols. Stuttgart/Paris: J.G. Cottae-Jul. Renouard.

[ISTC] Incunabula Short Title Catalogue. London: British Library. En línea: <http://www.bl.uk/catalogues/istc> [consulta: 15/06/2021].

LAMARCA, Montserrat y Jordi TorRA (1995), Catàleg dels incunables de la Universitat de Barcelona. Barcelona: Publicacions de la Universitat de Barcelona.

Martí Grajales, Francisco (1927), Ensayo de un diccionario biográfico y bibliográfico de los poetas que florecieron en el Reino de Valencia hasta el año 1700. Madrid: Tip. de la «Revista de Archivos, Bibliotecas y Museos»». 
Martínez Romero, Tomàs (2015), «Escriptors a la València de la segona meitat del segle Xv», en Lola Badia (ed. y dir.), Història de la Literatura Catalana, 3. Barcelona: Enciclopèdia Catalana/Editorial Barcino/Ajuntament de Barcelona, pp. 305-355.

MARTos, Josep Lluís (2008), «La literatura perduda de Joan Roís de Corella: les fonts», Caplletra, 45, pp. 93-112.

MarTos, Josep Lluís (2015), «La literatura perdida de Joan Roís de Corella: límites, proceso y resultados de un catálogo», en Carlos Alvar (ed.), Estudios de literatura medieval en la Península Ibérica. San Millán de la Cogolla: Cilengua, pp. 123-145.

Martos, Josep Lluís (2016a), «Un incunable de Pere Trincher: tipografía, decoración y datación», Revista de poética medieval, 30, pp. 199231. DOI: https://doi.org/10.37536/RPM.2016.30.0.51071.

Martos, Josep Lluís (2016b), «Un cancionero incunable valenciano: descripción bibliográfica, estructura y contextos», en María Jesús Lacarra (ed.), La literatura medieval hispánica en la imprenta (14751600). Valencia: Universitat de València, pp. 173-189.

MarTos, Josep Lluís (2016c), «La Suplicació de natura humana de Joan Roís de Corella: fragmentos recuperados de una obra perdida», Cultura Neolatina, 75/1-2, pp. 165-201.

MarTos, Josep Lluís (2018), «Fuentes poéticas incunables: el cancionero 87FD y Juan Tallante», en Andrea Zinato y Paola Bellomi (eds.), Poesía, poéticas y cultura literaria. Como/Pavia: Ibis, pp. 523-533.

MARTos, Josep Lluís (2019a), «Materialitat i errors de composició d'un incunable poètic (b2/87FD): la rendibilitat ecdòtica», Magnificat Cultura i Literatura Medievals, 6, pp. 165-184.

MARTOS, Josep Lluís (2019b), «Estructura de un incunable poético: la Obra de la Sacratíssima Concepció de la intemerada Mare de Déu», Hispanófila, 187, pp. 145-162.

MarTos, Josep Lluís (2019c), «Los ejemplares del incunable poético 87FD», en María Jesús Lacarra (coord.), Nuria Aranda, Ana M. Jiménez y Ángela Torralba (eds.), Literatura medieval hispánica. Libros, lecturas y reescrituras. San Millán de la Cogolla: Cilengua, pp. 753-768.

Martos, Josep Lluís (2019d), «Orationes ad laudem purissime conceptiones virginis Marie: recuperación de un incunable / literatura recuperada», Revista de Literatura Medieval, 31, pp. 63-93. DOI: https:// doi.org/10.37536/RPM.2019.31.0.73733.

MARTOS, Josep Lluís (2020a), «El cancionero 87FD en la bibliografía ilustrada: desatención a lo material y generación de fantasmas», en «Et era muy acuçioso en allegar el saber». Studia Philologica in Honorem Juan Paredes. Granada: Universidad de Granada, pp. 541-558.

MarTos, Josep Lluís (2020b), «Exemplar(s) d'un incunable retrobat: Orationes ad laudem Purissime Conceptionis Virginis Marie 
(València, Lambert Palmart, 1489)», en Miscel-lània Antoni Ferrando, 1. Barcelona: Publicacions de l'Abadia de Montserrat («Estudis de Llengua i Literatura Catalanes», 74), pp. 113-133.

Martos, Josep Lluís (2021), «Les trobes en lahors de la verge Maria: historiografía de un incunable poético ¿sine notis?», Criticón, 141, pp. 15-36. DOI: https://doi.org/10.4000/criticon.18914.

MarTos, Josep Lluís (en prensa), «Contenidos y génesis de un incunable perdido», en Anna I. Peirats (ed.), Isabel de Villena i l'espiritualitat europea tardomedieval. Valencia: Tirant lo Blanc.

MAsSÓ I TORRENTS, Jaume (1913-1914), «Bibliografia dels antichs poetes catalans», Anuari de l'Institut d'Estudis Catalans, 5, pp. 2-276.

Massó I ToRrents, Jaume (1932), Repertori de l'antiga literatura catalana: la poesia, 1. Barcelona: Editorial Alpha.

MÉNDEZ, Francisco (1861), Tipografia española ó Historia de la introducción, propagación y progresos del arte de la imprenta en España. 2. ${ }^{a}$ ed. Edición corregida y adicionada por Dionisio Hidalgo. Madrid: Imprenta de las Escuelas Pías [1. ${ }^{a}$ ed.: Madrid: Viuda de Ibarra, 1796].

Miquel i Planas, Ramon (ed.) (1913), Obres de J. Roiç de Corella. Barcelona: Casa Miquel-Rius.

Palau y Dulcet, Antonio (1948-1977), Manual del librero hispanoamericano. Barcelona: Librería Palau, 28 vols.

Ribelles Comín, José (1915), Bibliografia de la lengua valenciana, o sea, catálogo razonado por orden alfabético de autores de libros, folletos, obras dramáticas, periódicos, coloquios, coplas, chistes, discursos, romances, alocuciones, cantares, gozos, etc., que escritos en lengua valenciana y bilingüe, han visto la luz pública desde el establecimiento de la imprenta en España hasta nuestros días, 1. Madrid: Imprenta de la Revista de Archivos, Bibliotecas y Museos.

RIERA I SANS, Jaume (1993), «Falsos dels segles XIII, XIV i XV», en Antoni Ferrando Francés, Lluís Meseguer, Rafael Alemany Ferrer (eds.), Actes del Novè Col-loqui Internacional de Llengua i Literatura Catalanes (Alacant-Elx, 9-14 de setembre de 1991), 1. Alacant/Castelló de la Plana/València, Publicacions de l'Abadia de Montserrat, pp. 425-491.

RiQuer, Martín de y Antoni Comas (1964), Història de la literatura catalana, 3. Barcelona: Ariel.

RodríGuEZ, Josep (1747), Biblioteca valentina. Valencia: Joseph Thomàs Lucas, impressor.

Romero LuCas, Diego (2005), Catálogo gráfico descriptivo de la imprenta en Valencia 1473-1530. Valencia: Universitat de València [tesis doctoral].

Salvá y Mallén, Pedro (1872), Catálogo de la biblioteca de Salvá, 2 vols. Valencia: Imprenta de Ferrer de Orga.

SERRANO y Morales, José Enrique (1898-1899), Reseña histórica en forma de diccionario de las imprentas que han existido en Valencia 
desde la introducción del arte tipográfico en España hasta el año 1868 con noticias bio-bibliográficas de los principales impresores. Valencia: Imprenta de F. Doménech.

Stillwell, Margaret Bingham (1940), Incunabula in American Libraries. A Second Census of Fifteenth-Century Books Owned in the United States, Mexico, and Canada. New York: The Bibliographical Society of America.

[TW] Typenrepertorium der Wiegendrucke, Staatsbibliothek zu Berlin. En línea: <https://tw.staatsbibliothek-berlin.de/> [consulta: 15/06/2021]. VINDEL, Francisco (1946), El arte tipográfico en España durante el siglo XV: Valencia, Mallorca y Murcia. Madrid: Dirección General de Relaciones Culturales.

VINDEL, Francisco (1951), El arte tipográfico en España durante el siglo XV. Dudosos de lugar de impresión. Adiciones y correcciones a toda la obra. Madrid: Dirección General de Relaciones Culturales.

Wittuin, Curt J. (1995), «Un text inèdit de Joan Roís de Corella: La visió a la porta de la Senyora Nostra de Gràcia, del 1487», A Sol Post, 3, pp. 257-268.

Ximeno, Vicente (1747-1749), Escritores del Reyno de Valencia cronológicamente ordenados desde el año MCCXXXVIII de la christiana conquista de la misma ciudad, hasta el MDCCXLVIII. Valencia: Imp. Josep Estevan Dolz, 2 vols. 


\title{
$\cos$
}

\section{OBRA EN PROSA SOBRE LA VERÍSSIMA INMACULADA CONCEPTIÓ de la Mare de DÉU (Valencia, Lambert Palmart, 1488): ESTUDIO MATERIAL DE UN INCUNABLE PERDIDO}

\begin{abstract}
RESUMEN: Este trabajo ofrece la primera descripción material de un incunable desconocido por los principales catálogos y repertorios internacionales, al haberse difundido en bibliografía de alcance muy parcial, restringida a escasos estudios filológicos de una tradición literaria concreta. La pertenencia del incunable a una biblioteca privada de un bibliófilo catalán ha contribuido a esto. Su paradero es hoy desconocido, si bien se reprodujo en microfilm en 1963. Está impreso por Lambert Palmart en Valencia, el 28 de junio de 1488, y forma parte de una trilogía patrocinada por Ferrando Díeç, como editor. Se avanza en el conocimiento y en el estudio material de este incunable perdido, con lo que ello implica como propuesta metodológica, atendiendo a estrategias de comparación y considerando para ello recursos de tratamiento digital.
\end{abstract}

Palabras Clave: Incunable. Lambert Palmart. Valencia. Ferrando Díeç. Inmaculada Concepción.

\section{WORK IN PROSE ON THE VERY IMMACULATE CONCEPTION of the Virgin Mary (VAlencia, Lambert Palmart, 1488): MATERIAL STUDY OF A LOST INCUNABULUM}

\begin{abstract}
This work offers the first material description of an unknown incunabulum by the main international catalogues and repertoires, as it has been published in a bibliography of very partial scope, restricted to few philological studies of a specific literary tradition. The incunabulum belonging to a private library of a Catalan bibliophile has contributed to this. Its whereabouts are unknown today, although it was reproduced on microfilm in 1963. It is printed by Lambert Palmart in Valencia on June 28, 1488, and is part of a trilogy sponsored by Ferrando Díeç, as editor. Progress is being made in the knowledge and material study of this lost incunabulum, with what this implies as a methodological proposal, attending to comparison strategies and considering resources for this digital treatment.
\end{abstract}

KeYwords: Incunabulum. Lambert Palmart. Valencia. Ferrando Díeç. Immaculate Conception. 